\title{
Молочные реки России *
}

С.Ю. БАРСУКОВА, доктор социологических наук, Национальный исследовательский университет «Высшая школа экономики», Москва. E-mail: svbars@mail.ru

Молочный рынок России переживает не лучшие времена: девальвация национальной валюты, падение доходов населения, трудность доступа к кредитным ресурсам создают проблемы для развития отрасли. Вместе с тем продовольственное эмбарго устанавливает режим протекционистской защиты этого рынка, снижая конкуренцию со стороны импортных молочных продуктов из ряда «подсанкционных» стран. Как реагирует молочный рынок на эти процессы? Какова ситуация на рынке молочного животноводства? Как реализуется курс на импортозамещение на молочном рынке России?

Ключевые слова: производство молока, потребление молока,

молочное животноводство, продуктивность молочного

стада, импортозамещение

\section{Сколько производится молока в России? Кем и где?}

В России производится чуть более 30 млн т молока, что означает почетное шестое место в мире. Но это валовый показатель, внушительность которого обусловлена размером страны. На душу же населения в России производилось в 2014 г. молока в 3,5 раза меньше, чем в Республике Беларусь (211 кг и 708 кг соответственно), и примерно в полтора-два раза меньше, чем в Германии и Франции. Ближе всего к нам по душевому производству молока стоят Армения и Великобритания. Существенно меньше на душу населения производят молока в Китае, Японии, Индии и Таджикистане.

Но любопытный факт: лишь немногим более половины российского молока носит товарный характер (60\% в 2010 г. и 64\% в 2014 г.), то есть поступает на переработку и дальше - на прилавки. Это то молоко, которое преимущественно производят сельскохозяйственные организации, чья товарность составляет $94 \%$. Поэтому при общем показателе производства молока в 2014 г. на уровне 30,8 млн т, объем реализации этого продукта составил только 19,7 млн т. Остальное молоко - произведенное в основном в личных подсобных хозяйствах населения (ЛПХ) - существует,

* Исследование осуществлено в рамках Программы фундаментальных исследований НИУ ВШЭ в 2016 г. 
скорее, как статистический артефакт. Никто не знает, куда оно уходит, и было ли оно на самом деле. Объяснение «Сами произвели и сами выпили» (споили телятам, разлили и пр.) заставляет вспомнить вопрос из рекламного ролика: «А ты не лопнешь, деточка?». Почти половина российского молока не появляется на прилавках, но поддерживает статистику на плаву.

Кто же производит молоко? Главными производителями молока примерно в равных долях являются сельскохозяйственные организации и ЛПХ. Вклад фермеров в молочный рынок, несмотря на положительную динамику, несопоставим. Так, в 2014 г. из 30,79 млн т российского молока сельхозорганизации произвели 14,36 млн т, ЛПХ - 14,51, фермеры - 1,92 млн т (табл. 1). В динамике можно констатировать рост доли фермеров (включая индивидуальных предпринимателей), достигшей примерно 6\%. Но в целом производство молока в РФ остается уделом сельхозорганизаций и ЛПХ: в 2014 г. их вклад в молочные реки России составил 46,7\% и 47,1\% соответственно (табл. 2).

\section{Таблица 1. Динамика производства молока в Российской Федера-} ции по категориям хозяйств в 1990-2014 гг., млн т

\begin{tabular}{|l|c|c|c|c|c|c|}
\hline \multicolumn{1}{|c|}{ Организации } & $\mathbf{1 9 9 0}$ & $\mathbf{1 9 9 5}$ & $\mathbf{2 0 0 0}$ & $\mathbf{2 0 0 5}$ & $\mathbf{2 0 1 0}$ & $\mathbf{2 0 1 4}$ \\
\hline Хозяйства всех категорий & 55,72 & 39,24 & 32,26 & 31,07 & 31,85 & 30,79 \\
\hline Сельскохозяйственные & 42,45 & 22,41 & 15,27 & 14,00 & 14,31 & 14,36 \\
\hline Хозяйства населения & 13,26 & 16,25 & 16,42 & 16,09 & 16,05 & 14,51 \\
\hline $\begin{array}{l}\text { Крестьянские (фермерские) } \\
\text { и индивидуальные предприниматели }\end{array}$ & - & 0,58 & 0,57 & 0,98 & 1,48 & 1,92 \\
\hline
\end{tabular}

Таблица 2. Производство молока в Российской Федерации по категориям хозяйств в 1990-2014 гг., \%

\begin{tabular}{|l|c|c|c|c|c|c|}
\hline \multicolumn{1}{|c|}{ Организации } & $\mathbf{1 9 9 0}$ & $\mathbf{1 9 9 5}$ & $\mathbf{2 0 0 0}$ & $\mathbf{2 0 0 5}$ & $\mathbf{2 0 1 0}$ & $\mathbf{2 0 1 4}$ \\
\hline Сельскохозяйственные & 76,2 & 57,1 & 47,3 & 45,1 & 44,9 & 46,7 \\
\hline Хозяйства населения & 23,8 & 41,4 & 50,9 & 51,8 & 50,4 & 47,1 \\
\hline $\begin{array}{l}\text { Крестьянские (фермерские) } \\
\text { и индивидуальные предприниматели }\end{array}$ & - & 1,5 & 1,8 & 3,1 & 4,7 & 6,2 \\
\hline
\end{tabular}

Такое положение дел резко контрастирует с опытом ведущих аграрных держав. Несмотря на усиление специализации и рост размера среднего земельного надела, что является общим трендом развития мирового аграрного производства, семейное фермерское хозяйство было и остается основой сельского хозяйства США и стран Европейского союза. 
Аграрная реформа в России началась со слов о том, что на смену советским колхозам и совхозам должны прийти семейные фермерские хозяйства, работающие «на себя» и на своей земле. Однако результат оказался иным: производство сконцентрировалось в рамках сельскохозяйственных организаций, что сделало наемный труд основой аграрного производства. При этом каждое пятое крупное и среднее сельскохозяйственное предприятие, согласно переписи 2006 г., входит в агрохолдинги, установившие контроль над миллионами гектаров и тысячами деревень. Вместо советских колхозов и совхозов получились крупные и сверхкрупные агрохолдинги с колоссальной бюрократией и мощным лоббистским напором. Прежнее плановое госфинансирование и регулярное списывание убытков сменились разнообразными формами государственных дотаций и субсидий, доступ к которым тем вероятнее, чем крупнее предприятие. Получилась своеобразная реинкарнация совхозов, но в рыночном варианте.

Но даже при значительной административной и финансовой поддержке агрохолдинги, за редким исключением, не занимаются молочным животноводством. Среди 20 крупнейших агрохолдингов России по выручке за 2014 г. верхние строчки рейтинга занимают производители свинины и птицы, а также занятые в растениеводстве («Мираторг», «Черкизово», «Эфко», «Русагро» и пр.). В «Топ-20» попал только один агрохолдинг с молочной специализацией - «Эконива».

Фермеры оказались на обочине экономических процессов. А те из них, кто пытается что-то сделать, предпочитают заниматься растениеводством, - лишь четверть фермерской продукции связана с животноводством. В результате в российские молочные реки впадают два рукава - продукция сельскохозяйственных организаций и ЛПХ. И тоненький ручеек фермерства. Правда, надо учитывать, что Росстат определяет объем молочного производства в подсобных хозяйствах населения, исходя из данных сельскохозяйственной переписи 2006 г. А это само по себе задает пределы доверия к этим цифрам. Очередная сельскохозяйственная перепись пройдет в 2016 г., и, видимо, обновленные данные по ЛПХ сделают нашу аграрную статистику значительно тревожнее. 
Но даже принимая за полную и безусловную правду данные Росстата, надо признать, что за 2009-2014 гг. производство молока в России сокращалось ежегодно примерно на $1 \%$. Продовольственное эмбарго, введенное в августе 2014 г., не переломило этот тренд, хотя и снизило крен падения. Так, в январесентябре 2015 г. по отношению к аналогичному периоду 2014 г. спад производства молока составил $0,3 \%$. Так что молочные реки отнюдь не выходят из берегов.

В каких регионах производится российское молоко? Молочной «житницей» России являются шесть субъектов РФ, в каждом их которых в год производится свыше 1 млн т молока. Это Краснодарский край, Ростовская и Саратовская области, республики Татарстан и Башкортостан, Алтайский край. Практически не производится молоко (менее 100 тыс. т в год) на севере и северозападе России (Карелия, Мурманская область, Республика Коми, Ямало-Ненецкий и Ханты-Мансийский автономные округа), на юге Сибири (Тыва и Республика Алтай) и на Дальнем Востоке (Чукотка, Камчатка, Магаданская и Сахалинская области, Хабаровский край).

Но людей больше интересует не то, сколько производится, а достаточно ли потребляется. Примем за «рекомендуемую норму» 320-340 кг молока и молокопродуктов в год на человека, что соответствует Приказу Министерства здравоохранения и социального развития от 2 августа 2010 г. (№ 593н). Ситуация нерадостная: в постсоветской России потребление молока хронически отстает от «нормы». Больше нормы россияне потребляли молока и молочных продуктов в 1990-1991 гг. (387 и 347 кг в год на душу населения). Потом произошло быстрое обрушение рынка, и в новейшей истории России не было ни одного года, когда бы вышли на сопоставимые показатели.

Сорвавшись с советских высот, потребление молока и молочных продуктов «средним россиянином» сократилось с 1990 г. по 2014 г. на $37 \%$ и «топчется» в последние годы на уровне 240-250 кг в год. Это при расчете по балансам продовольственных ресурсов, что включает потребление в тюрьмах, колониях, больницах, интернатах и т. д. Очевидно, что там не балуют. Поэтому имеет смысл взять показатель среднедушевого потребления молока и молочных продуктов, рассчитанный по обследованиям бюджетов домохозяйств. В этом случае показатель среднеду- 
шевого потребления возрастает, но несущественно, составив в 2013 г. 270 кг.

Особо отметим, что потребление молока и молочных продуктов в сельской местности на 10\% ниже, чем в городе. Таким образом, уровень достижения рациональных норм по молоку и молочным продуктам составлял в России в 2013 г. 75\% по данным балансов и $82 \%$ - по данным бюджетных обследований домохозяйств. Примерно так же обстоят дела по овощам, фруктам и ягодам, но с той существенной разницей, что потребление овощей в последние годы быстро растет, чего нельзя сказать о молоке и молочных продуктах [1].

Кстати, в этих цифрах есть намек на лукавость официальной статистики: если половина молока производится в ЛПХ и там же остается ввиду их низкой товарности, то почему, согласно обследованиям бюджетов сельских домохозяйств, селяне потребляют молока меньше горожан? Смутные догадки о фиктивности производства молока в ЛПХ получают дополнительную опору.

Впрочем, если отвлечься от некоей «нормы» в понимании Минздрава, то ситуация вполне пристойная: потребление на душу населения молока и молочных продуктов, включая масло животное (в пересчете на молоко), ставит Россию в ряд с такими странами, как США, Франция, Великобритания, Австрия, Германия. Существенно больше потребляют молока и молочных продуктов на душу населения в Нидерландах (349 кг) и Финляндии (460 кг), а гораздо меньше - в Японии (89 кг), Чехии (178 кг), Венгрии (189 кг) и в бывших республиках СССР - Таджикистане (130 кг), Молдове (166 кг), Туркмении (178 кг) и Узбекистане (160 кг).

Но говоря о потреблении «среднего» россиянина, следует учесть, что такового нет. Все проще и циничнее: молочные продукты доступны обеспеченным гражданам, а низкодоходные группы испытывают его недостаток, компенсируя повышенным потреблением картофеля и хлебобулочных изделий, достигающим в среднедушевом рационе россиян 118\% и $114 \%$ от нормы соответственно. Этот разрыв усугубляется ростом цен на молочные продукты (в 2015 г. - на 13,7\%). Вопрос времени, когда это скажется на здоровье нации.

При этом есть регионы РФ, где в среднем на человека приходятся заветные 320 кг, а где-то - менее 200 кг. При этом география производства молока и его потребления не совпадают. Больше 
всего (свыше 320 кг молока и молокопродуктов на душу населения) потребляют в Алтайском крае, Карачаево-Черкесии и Татарстане. Совсем мало, менее 200 кг на человека, - в Республике Тыва, на Дальнем Востоке (Амурская, Еврейская, Сахалинская области, Приморский и Камчатский края, Чукотка), в Уральском ФО (Ямало-Ненецкий и Ханты-Мансийский АО, Тюменская и Челябинская области), на Северо-Западе (Архангельская область) и в Центральном ФО (Тамбовская и Тульская области), а также в Крымском ФО. То есть льют молоко в бидоны в одном месте, а пьют - в другом, что связано с традициями питания и региональной дифференциацией платежеспособного спроса.

\section{Поголовье и продуктивность стада: разнонаправленная динамика}

Производство молока - показатель, производный от поголовья и продуктивности. Возможны как синхронное падение (или рост) этих показателей, так и их различная динамика. Как с этим обстоят дела в России? Продуктивность молочного стада в России в целом растет (табл. 3). Так, с 2009 г. по 2014 г. средние надои на одну корову в хозяйствах всех категорий увеличились с 3,7 до 4,0 т (на $8 \%$ ) в год. Локомотивом этого роста были сельхозорганизации, где рост продуктивности молочного стада составил за эти пять лет $18 \%$. В результате увеличения продуктивности производство молока в корпоративном секторе растет, несмотря на снижение поголовья. У фермеров средние надои на корову поднялись на $6 \%$. Продуктивность молочного стада в хозяйствах населения не изменилась. Одна «средняя корова» в 2014 г. давала в ЛПХ и в фермерском хозяйстве примерно 3,5 т молока в год, а в сельскохозяйственных организациях $-4,8$ т.

Таблица 3. Надои молока в год на 1 корову по категориям хозяйств в 1990-2014 гг., кг

\begin{tabular}{|l|c|c|c|c|c|c|}
\hline \multicolumn{1}{|c|}{ Организации } & $\mathbf{1 9 9 0}$ & $\mathbf{1 9 9 5}$ & $\mathbf{2 0 0 0}$ & $\mathbf{2 0 0 5}$ & $\mathbf{2 0 1 0}$ & $\mathbf{2 0 1 4}$ \\
\hline Хозяйства всех категорий & 2731 & 2153 & 2502 & 3176 & 3776 & 4021 \\
\hline Сельскохозяйственные & 2783 & 2016 & 2341 & 3280 & 4189 & 4841 \\
\hline Хозяйства населения & 2576 & 2388 & 2687 & 3130 & 3510 & 3501 \\
\hline $\begin{array}{l}\text { Крестьянские (фермерские) } \\
\text { и индивидуальные предприниматели }\end{array}$ & 4448 & 1989 & 2253 & 2607 & 3291 & 3450 \\
\hline
\end{tabular}

Много это или мало? Для сравнения напомним, что в 1991 г. средние надои в Восточной Германии (бывшей ГДР) составляли 
4,5 т, а в 2012 г. - уже 9 тыс. л молока на «среднюю» корову. То есть по показателю продуктивности молочного стада современная Россия находится на уровне бывшей ГДР на момент ее объединения с ФРГ. Конечно, и у нас есть отдельные, наиболее технически оснащенные предприятия, где надои с одной коровы достигают 10 т в год. И эти предприятия служат маяком для аграрной политики, которая однозначно разворачивается в сторону крупного индустриального производства. Без сантиментов, со ссылками на надвигающийся кризис и необходимость импортозамещения, аграрная политика отказывается от курса на многоукладность сельского хозяйства, поворачиваясь спиной к фермерам и ЛПХ.

Так, одним из направлений национального приоритетного проекта «Развитие АПК» (2006-2007 гг.) была поддержка личных подсобных хозяйств населения и фермерства. Теперь же позиция Минсельхоза изменилась: поддержку получают только индустриально организованные аграрные производства, что означает отказ от помощи ЛПХ. Проблема состоит в том, что под «индустриальными» чиновник подразумевает «крупные» хозяйства. В аграрной политике эти слова стали синонимами.

Да, фермерские хозяйства существенно отстают по надоям от показателей крупных агрохолдингов, но если бы на создание и модернизацию семейных молочных ферм были потрачены средства, сопоставимые с теми, что получили агрохолдинги, то сравнение с высокой вероятностью было бы не в пользу крупных производств. Однако проверить это уже невозможно, - подавляющая часть государственной помощи ушла в одни ворота. И эти ворота остаются широко распахнутыми. Например, О. Фадеева провела анализ деятельности новосибирской компании крупнейшего российско-немецкого холдинга по производству сырого молока. Согласно ее расчетам, в 2013 г. (спустя пять лет с начала своей деятельности) эта компания получила 178,7 млн руб. государственной поддержки, что в 8,8 раза превысило ее прибыль [2].

Почему же тогда нет роста производства молока? Потому что незначительное увеличение продуктивности накладывается на существенное сокращение поголовья: современная Россия имеет стадо коров, составляющее менее $40 \%$ от того, что было в 1990 г. (табл. 4). Впрочем, сравнение с тем временем не вполне корректно. В советский период делали ставку на развитие так 
называемых мясо-молочных пород, тогда как весь мир пошел по пути разделения молочного и мясного бизнеса. Потребовались годы для структурной перестройки этой отрасли. Но и в последние пять лет поголовье коров ежегодно продолжает сокращаться в среднем на $1 \%$.

Таблица 4. Поголовье коров в России по категориям хозяйств в 1990-2014 гг., млн голов

\begin{tabular}{|l|c|c|c|c|c|c|}
\hline \multicolumn{1}{|c|}{ Организации } & $\mathbf{1 9 9 0}$ & $\mathbf{1 9 9 5}$ & $\mathbf{2 0 0 0}$ & $\mathbf{2 0 0 5}$ & $\mathbf{2 0 1 0}$ & $\mathbf{2 0 1 4}$ \\
\hline Хозяйства всех категорий & 20,557 & 17,436 & 12,743 & 9,522 & 8,844 & 8,531 \\
\hline Сельскохозяйственные & 15,322 & 10,455 & 6,487 & 4,282 & 3,713 & 3,440 \\
\hline Хозяйства населения & 5,235 & 6,705 & 5,940 & 4,827 & 4,412 & 4,005 \\
\hline $\begin{array}{l}\text { Крестьянские (фермерские) } \\
\text { и индивидуальные предприниматели }\end{array}$ & - & 0,276 & 0,259 & 0,413 & 0,719 & 1,086 \\
\hline
\end{tabular}

При этом, согласно статистике, совокупное стадо в крестьянских (фермерских) хозяйствах даже немного подросло, но на фоне заметного снижения поголовья в сельхозорганизациях и хозяйствах населения, на которые приходится соответственно $40 \%$ и $47 \%$ российского стада коров (табл. 5). Заметим, что эти цифры включают также коров мясного направления. Реальное молочное стадо в сельскохозяйственных организациях насчитывает не более 2,5 млн голов. Касательно того статистического факта, будто бы каждая вторая корова содержится в ЛПХ, напомним, что это восходит к данным сельскохозяйственной переписи десятилетней давности. Можно предположить, что предстоящая в 2016 г. перепись сильно скорректирует эту картину.

Таблица 5. Поголовье коров в России по категориям хозяйств в 1990-2014 гг., \%

\begin{tabular}{|l|c|c|c|c|c|c|}
\hline \multicolumn{1}{|c|}{ Организации } & $\mathbf{1 9 9 0}$ & $\mathbf{1 9 9 5}$ & $\mathbf{2 0 0 0}$ & $\mathbf{2 0 0 5}$ & $\mathbf{2 0 1 0}$ & $\mathbf{2 0 1 4}$ \\
\hline Сельскохозяйственные & 74,5 & 60 & 50,9 & 45,0 & 42,0 & 40,3 \\
\hline Хозяйства населения & 25,5 & 38,4 & 47,1 & 50,7 & 49,9 & 47,0 \\
\hline $\begin{array}{l}\text { Крестьянские (фермерские) } \\
\text { и индивидуальные предприниматели }\end{array}$ & - & 1,6 & 2,0 & 4,3 & 8,1 & 12,7 \\
\hline
\end{tabular}

К слову, современная Восточная Германия тоже имеет сокращение поголовья в два раза по сравнению с ГДР в 1990 г. Однако там общее производство молока сохранилось ввиду двукратного 
роста продуктивности молочного стада. У нас же сокращение поголовья обогнало рост надоев с одной коровы, что выразилось в отрицательной динамике производства молока.

О сокращении поголовья свидетельствует и ежегодное снижение количества доильных установок и агрегатов в сельском хозяйстве страны: в 1990 г. их было 242 тыс., в 2000 г. - 88,7 тыс., в 2014 г. - 26,3 тыс. (правда, очевидно, что снижение количества сопровождается значительным ростом производительности новой техники).

Тут не обойтись без небольшого отступления. Прошли те времена, когда аграрная сфера была синонимом отсталости и изолированности от научного прогресса. Пожалуй, самая большая проблема России - трагическое запаздывание в понимании того, что мир изменился, что именно агробизнес стал наиболее наукоемким сегментом производства. То, что происходит в современном сельском хозяйстве, по степени новизны можно сравнить лишь с прорывом человека в космос. И современная корова - это не Зорька из наших детских воспоминаний о каникулах в деревне. Это стоящая на четырех ногах мини-фабрика по производству молока или мяса. А чтобы «фабрика» работала, нужно полное технологическое соответствие ее обслуживания «проектной документации»: витамины по графику, корма по нормам и пр. И стоят эти современные Зорьки, закупаемые, кстати, преимущественно за рубежом по причине недальновидного сворачивания отечественной селекции и генетики, как детали космического корабля, что сближает сельское хозяйство и космос уже не в поэтическом, а в прозаическом смысле.

Техника для современной фермы, кормовые добавки, ветеринарные препараты при обвале российской валюты тоже достигли космических цен. Поэтому шансы на современное молочное животноводство прямо связаны с помощью государства. Похоже, достанется эта помощь только крупным и крупнейшим игрокам молочного рынка.

\section{Импортозамещение:} красивый лозунг и скромные результаты

Недостаток производства компенсируется импортом. Много ли молока и молочных продуктов мы завозим? В 2000-е годы 
импорт молока и молокопродуктов (в пересчете на молоко) составлял примерно 7-9 млн т с дифференциацией по годам: минимум пришелся на 2009 г. (7 млн т), а максимум - на 2013 г. (9,5 млн т) (табл. 6). Если считать, что Россия производит около 30 млн т молока, то получается, что примерно три четверти - собственное производство, а четверть - импорт. Если же соотнести импорт с товарным молоком, то оказывается, что пропорции иные: более трети молока и молочных продуктов в 2014 г. приходилось на импорт, а по отдельным позициям, например, по сырам, импорт составлял почти половину.

Таблица 6. Производство, импорт, экспорт молока

и молочных продуктов в РФ в 1995-2015 гг., тыс. т

\begin{tabular}{|l|c|c|c|c|c|c|}
\hline \multicolumn{1}{|c|}{ Показатель } & $\mathbf{1 9 9 5}$ & $\mathbf{2 0 0 0}$ & $\mathbf{2 0 0 5}$ & $\mathbf{2 0 1 0}$ & $\mathbf{2 0 1 4}$ & Январь-сентябрь 2015 \\
\hline Производство & 39241 & 32259 & 30826 & 31847 & 30791 & 24174 \\
\hline Импорт & 6317 & 4718 & 7115 & 8159 & 9155 & 4681 \\
\hline Экспорт & 396 & 507 & 493 & 460 & 629 & 449 \\
\hline
\end{tabular}

И тут наступил август 2014 г., когда правительство в ответ на антироссийские санкции запретило импорт ряда продовольственных товаров из «недружественных» стран, в том числе и молочных продуктов. В этой ситуации возможны два сценария: импортозамещение продовольствием собственного производства и смена географии импорта.

Что касается переориентации на импорт из стран, с которыми мы не успели поссориться, то здесь ожидания не слишком оптимистичные. Раздувая тему геополитического противостояния, отечественные СМИ прочно связывают сокращение импорта с «ответными мерами» российского правительства на антироссийские санкции. Однако это полуправда. Уменьшение импорта из стран ЕС на 45,4\% (за январь-апрель 2015 г. по сравнению с аналогичным периодом предыдущего года) можно гипотетически «списать» на санкции. Но как быть с тем фактом, что в этот же период заметно упали объемы импорта со стороны вполне дружественных нам стран - Вьетнама (14,4\%), Китая $(30,6 \%)$, Южной Кореи $(53,4 \%)$ ? И даже импорт из стран Евразийского экономического союза сократился на $37,7 \%$. Эти факты свидетельствуют о том, что реальные причины сокращения 
импорта в начале 2015 г. связаны не только и не столько с санкциями, сколько с экономическими проблемами - девальвацией рубля и падением платежеспособного спроса в российской экономике. Импорт не может сменить географию, гордо отказавшись от хорошо зарекомендовавших себя европейских брендов и перейти на другие страны. Обрушившийся рубль своими обломками накрыл этот сценарий.

Остается надежда на отечественных производителей. И действительно, в последнее время стали появляться новые предприятия по созданию молочных продуктов, новые отечественные молочные бренды (например, «Баба Валя»). Но рост собственного производства оказался скромным: за январь-октябрь 2015 г. по сравнению с аналогичным периодом прошлого года производство сливочного масла выросло на 3\%, цельномолочной продукции - на 1\%, сухой молочной продукции - наоборот, сократилось на 4\%. Феноменально резко взлетело производство сыров и сырных продуктов, достигнув 580 тыс. т, что на 20\% выше показателя годичной давности (табл. 7).

\section{Таблица 7. Изменение объемов отечественного производства и импорта (январь-октябрь), тыс. т}

\begin{tabular}{|c|c|c|c|c|}
\hline \multirow{2}{*}{ Продукция } & \multicolumn{2}{|c|}{ Импорт } & \multirow{2}{*}{$\begin{array}{c}\text { Изменение } \\
\text { объемов } \\
\text { импорта, \% }\end{array}$} & \multirow{2}{*}{$\begin{array}{c}\text { Изменение объемо } \\
\text { собственного } \\
\text { производства, \% }\end{array}$} \\
\hline & 2014 & 2015 & & \\
\hline Сливочное масло & 125 & 77 & $-38,5$ & +3 \\
\hline Сыр и сырные продукты & 249 & 142 & -43 & +20 \\
\hline Сухая молочная продукция & 162 & 236 & +45 & -4 \\
\hline
\end{tabular}

Казалось бы, этому можно только радоваться. Однако возникает вопрос: как такое возможно, если продовольственное эмбарго не вызвало бурного роста производства сырого молока? Сам министр сельского хозяйства А. Ткачев признал, что в России не хватает стада в 1 млн коров. О скудности сырьевой базы говорит и то, что 2015 г. ознаменовался резким ростом импорта сухого молока, причем 97\% его пришлось на Беларусь. Кроме того, проблемы экономики привели к снижению реальных доходов населения, в результате чего спрос на продовольствие смещается в нижний ценовой сегмент. 
Что делать, если покупатель нищает, а сырье становится дефицитным и, стало быть, более дорогим? Ответ очевиден: снижать себестоимость, замещая молочные жиры растительными. Однако в борьбе за покупателя производитель проявляет скромность и не помещает на этикетку упоминание об этой новации. То есть производит фальсификат. Импорт пальмового масла за январь-октябрь 2015 г. вырос на 25\%. Роспотребнадзор регулярно кого-то ловит, штрафует на 50 тыс. руб. и отпускает. Тем самым демонстрируется забота о населении, что немаловажно ввиду приближающихся выборов. Не более.

Вот как охарактеризовал ситуацию на рынке молочных продуктов предприниматель на специализированном сайте молочной отрасли: «Рентабельность производителей некачественных продуктов сумасшедшая. Те, кто делает натуральное масло, могут им только завидовать. А с сыром еще и другая проблема - там надо строить производство, вкладываться, инвестиции очень длинные. Так вот, наладить линию производства “бодяги” можно за три месяца, а чтобы построить нормальный завод по производству сыра, необходимо три года. В условиях экономической неопределенности мало кто видит смысл в это вкладываться. Сыром можно заниматься только ради идеи. У нас сыр пока продолжает “умирать”» [3]. Это публичное высказывание. Можно представить, как предприниматели оценивают ситуацию в кулуарах.

Продовольственное эмбарго обернулось радикальным ростом фальсификата на рынке молочных продуктов и нечестной конкуренцией против добропорядочных производителей. Особенно часто подделывают масло и сыры. По данным Россельхознадзора, на молочном рынке страны доля фальсификата составляет около $25 \%$, а в сегменте сыров - $78 \%$. Правда, Национальный союз производителей молока «Союзмолоко» опровергает эту оценку, утверждая, что только четверть сыров на российских прилавках фальсифицирована. Но вряд ли это можно считать оптимистической оценкой. В связи с массовой фальсификацией молочных продуктов активно обсуждаются поправки в техническом регламенте, который действует на территории стран Таможенного союза, об обязательном требовании сообщать о наличии пальмового масла на лицевой 
части этикетки. Беларусь уже заявила о согласии поддержать это требование. Ей это не страшно: сделав массированные вложения в молочную отрасль, страна имеет обширную сырьевую базу для производства качественных молочных продуктов. В отличие от России.

\section{$* * *$}

Итак, важнейшими итогами развития молочного рынка в 2015 г. следует признать:

- значительный рост фальсификата, особенно в сегменте сыров;

- существенный рост импорта сухого молока, преимущественно из Беларуси, как реакция на нехватку отечественного сырого молока;

- рост продуктивности молочного стада корпоративного сектора, что, несмотря на сокращение поголовья, ведет к росту производства сырого молока в сельскохозяйственных организациях;

- фокусирование государственной помощи на индустриальном производстве молока, что фактически означает ставку на крупных и крупнейших производителей.

\section{Литература}

1. Шагайда Н., Узун В. Продовольственная безопасность: проблема оценки // Вопросы экономики. - 2015. - № 5. - С. 63-78. 2. Фадеева О. «Дело было в Пенькове»: как агрохолдинги завоевывают сельские районы Сибири // Крестьяноведение: Теория. История. Современность. Ученые записки. Вып. 10; под ред. А. М. Никулина, М.Г. Пугачевой, Т. Шанина. - М.: Издательский дом «Дело» РАНХиГС, 2015. - С. 197-233.

3. URL: www.milknews.ru 